hunting is a way of life based on the harvesting of renewable resources (seals, whales, and other sea mammals), it is a way of life long made possible by the complex interplay between informal and formal economic activities. This is an important part of the book, because part of the strategy used by anti-whaling groups in their criticism of whaling communities in contemporary Greenland is to reify traditional hunting as something that is only permissible if hunters live within a 'non-commercial,' nonmarket-based economy and utilise simple technologies. Caulfield shows how this is a false premise.

It is Caulfield's view that Greenland's whale management policies, structured in terms of co-management, are effective, as far as they currently operate. However, he nonetheless points out that the present whaling regime is not without its problems and has resulted in political and cultural tensions within Greenland. Since 1979, Greenland has embarked on a process of nation-building, a process that has produced complex ideological oppositions evident between interest groups in a national context (such as political parties, hunters, fishermen, and producer organisations) rather than between local communities. In Greenland today, the whaling debate highlights some of these oppositions. In particular, conflicts arise over the use of science versus indigenous knowledge in whale management, the introduction of new technology for whale hunting, the ethics and morality of selling whale meat for cash rather than distributing it through traditional patterns of sharing and exchange, and the changing nature of power relations within and between communities as a result of participation in the international politics of whaling. There are also concerns expressed by hunters and local communities that the Greenland Home Rule Authorities do not give them a fair share of the IWC quota.

As the debate on aboriginal subsistence whaling enters a period when the concepts of 'aboriginality' and 'subsistence' will be redefined, and as questions are raised over whether co-management practices offer a compromise by merely regulating access to resources and do not allow the promise of greater self-regulation by Greenlanders, Caulfield has written a timely book that will appeal to Arctic specialists as well as those concerned with the politics of resource management elsewhere in the world. (Mark Nuttall, Department of Sociology, University of Aberdeen, Aberdeen AB24 3QY.)

\section{ANTARCTIC ENVIRONMENTAL PROTECTION: A COLLECTION OF AUSTRALIAN AND INTER- NATIONAL INSTRUMENTS. Donald R. Rothwell and Ruth Davis (Editors). 1997. Sydney: Federation Press. xii + 306 p, hard cover. ISBN 1-86287-271-6.}

The Antarctic Treaty System (ATS) has long been the subject of academic scrutiny and analysis, and has generated a significant volume of literature. With the entry into force of the Madrid Protocol on Environmental Protection in January 1998, it is unlikely this situation will change in the immediate future. For those wishing to examine the
Treaty and the other constituent elements of the ATS, it has always been somewhat frustrating that the relevant documents are scattered through a variety of sources, not easily lending themselves to access. Until recently, only Bill Bush's Antarctica and international law sought to centralise the primary source material concerning the Antarctic. The only limitation to Bush's excellent work is its thoroughness, as the original edition covered four volumes, and it has subsequently expanded as much again in a looseleaf service. The size of the book, and therefore the attendant cost, meant that its possession was restricted to those with a strong research interest in the field, or to specialist libraries. Consequently, it might be argued that a place existed for a work providing a compilation of the more significant Antarctic materials, a work that could have a wider degree of availability. This appears to be the objective of Antarctic environmental protection, edited by Donald R. Rothwell and Ruth Davis.

The book itself is divided into two parts. The first half considers the international instruments that make up the ATS, namely the Antarctic Treaty itself, the Convention for the Protection of Antarctic Seals, the Convention for the Conservation of Antarctic Marine Living Resources (CCAMLR), and the Madrid Protocol. In addition are certain key Recommendations and Measures adopted at Antarctic Treaty Consultative Party Meetings and CCAMLR meetings. These latter materials are particularly welcome, as they are seldom extracted in articles or monographs. The Measures selected were chosen with an eye to their relevance to the broader environmental issues that have faced the Antarctic in the last decade, notably tourism, mineral-resource activities, area management, and living-resource exploitation. With regard to this last category, it is particularly pleasing to see extracted the provisions dealing with exploratory fisheries under CCAMLR. These provisions are occasionally overlooked by authors considering CCAMLR, yet they are an important plank in implementation of a precautionary approach within the CCAMLR area.

The second part is directed towards the legislative implementation of the ATS within Australia. Each of the principal acts, stretching back to Australia's acceptance of the Australian Antarctic Territory in the 1930s, through to the scheme to implement the totality of the Madrid Protocol, is extracted. While this will be of principal benefit to Australian researchers, it may be of interest to researchers elsewhere, curious to see what form an overall legislative response to a state's Antarctic obligations has taken. Rarely has all of a state's Antarctic legislation been condensed together in so convenient a form. In addition, an Initial Environmental Evaluation, submitted under the Australian legislation, is extracted. This is particularly useful, as it provides an insight into the actual scope of the commitment each state party has made, which may be difficult to gauge when reading a commentary or legislation alone.

In addition to the primary source material, each of the 
two parts is prefaced by a short commentary. The commentaries are succinct and provide a neat summation of the content and background of the documents they precede. While more detail in relation to many of the issues surrounding the Antarctic Treaty would have been welcome, for example concerning the significance of Article IV of the Antarctic Treaty, it is clear that the commentaries were intended to merely introduce topics rather than expound at length. In this task, they do an admirable job in informing the reader of an issue where it does exist, and the extensive accompanying bibliography indicates where further information can be sought. Short commentaries also precede each instrument, providing a context in which the material can be better appreciated and related to the other materials.

In short, this book is a useful tool for those engaged in research into the Antarctic Treaty, and into Australia's legislative responses to its Antarctic obligations. Its convenient size and content make it ideal for students, particularly those in Australian universities, approaching the ATS for the first time. Given, too, the heightened awareness and relevance of the ATS resulting from the entry into force of the Madrid Protocol, the book is also timely. (Stuart Kaye, Faculty of Law, University of Tasmania, GPO Box 25289, Hobart, Tasmania 7001, Australia.)

GAINING GROUND? EVENKIS, LAND, AND REFORM IN SOUTHEASTERN SIBERIA. Gail A. Fondahl. 1998. Boston, London, Toronto: Allyn and Bacon (Cultural Survival Studies in Ethnicity and Change Series). xiv + 146 p, illustrated, soft cover. ISBN 0-20527579-6.

This short book is the first monograph of a well-read and well-travelled scholar of Siberian Evenki culture. Gail Fondahl has been collecting archival and oral accounts of Evenki reindeer pastoralism since 1987 and has pioneered a colloborative research project that has introduced Evenki political activists with their Canadian First Nation counterparts.

Given her long experience, this book captures only a slim part of Fondahl's accumulated field material. The intention of the work, as the series editors proclaim, is to provide a 'short, clear and accessible' account of an Evenki land tenure. The book to a great extent meets these objectives, but at many points the reader is left wanting either more detail or more explanation as to the significance of the presented facts.

The title points to the central theme of the book: have recent reforms since the fall of the Soviet state allowed this Siberian minority to negotiate a closer relationship with their land? The author argues that although the formation of recent 'clan' obshina territorities have given this aboriginal nation more control over parcels of territory than they enjoyed in Soviet times, the relationship to these parcels is much more limited and fragile than the autonomy experienced in the pre-Soviet period. To make this nuanced argument, Fondahl marshals a wealth of historical evidence to establish how Evenki land tenure has changed over time. In fact, of seven chapters, three are devoted to sketching out the different institutional settings of Evenki pastoralism from tsarist times, through the time of the revolution and subsequently collectivization, to the centralising reforms of the late Soviet period. These chapters set the stage, as it were, for the evaluation of the contemporary life of Evenki hunters and herders to be found in chapters six and seven.

The technique of understanding the ambiguity of the present through a recapitulation of the past is a well-worn trope in Soviet regional studies. To give credit to the author, it is a narrative technique that most middle-aged informants in the Russian Federation use themselves for communicating their life-histories. Most Russian language studies of Siberia mirror and reinforce this local style. In English, this narrative was most directly applied and analysed by Bruce Grant (1995) in his study of Nivkh village life. Fondahl borrows heavily from Grant's work by leaving us with the impression that the current market reforms are just one more 'perestroika' in a whole string of wrenching social experiments.

Of the several historical accounts of political change, by far the most valuable are from the tsarist period (chapter 3 ) and the early Soviet period (chapter 4). Drawing on rare archival documents and articles from regional journals, Fondahl sets Soviet colonial practice within a long history of Russian trade and mining in the region. Of special interest are her occasional observations of the effects of gold mining, institutionalised fur trapping, and military expansion on the landscape itself. Through each period, Evenkis are portrayed as somewhat passive but nonetheless capable actors within a complex state environment.

This account of several generations of reform in the rural areas to the east of Lake Baikal is enlivened by two literary illustrations of the flavour of Evenki life. In chapters 2 and 6 , the author gives a composite account of the struggles that fictional protagonists might experience both before the Revolution and following the collapse of Soviet state socialism. These accounts are penetrating in their detail and demonstrate the author's sympathy and understanding of the culture. The intimacy of these accounts, however, sits somewhat uncomfortably with the interval accounts of mechanisms of Tsarist and Soviet power. In each period, the reader is given very clear maps and a lot of detail of how Evenki hunters and herders were monitored and eventually dispossessed of their 'clan' territories. However, it remains unclear why generations of state servants pursued such harsh and damaging policies. The various institutional impacts of Russian and Soviet state policy on Evenkis are made very clear, but they come across as equally malicious, or at least uniformly insensitive and misguided. The sense of tragedy (or paradox) could have been sharpened if the paternalistic and sometimes altruistic motives of these colonisers were made clearer. This observation is not important for merely stylistic reasons, but it would help the reader understand the sense of caution and hesitation with which present-day 